\title{
The Cellulolytic Activity of Pure Strains of Bacteria from the Rumen of Cattle
}

\author{
By G. HALLIWELL \\ Department of Enzymology, Rowett Research Institute, Aberdeen \\ AND M. P. BRYANT \\ Dairy Cattle Research Branch, Agricultural Research Centre, \\ U.S. Department of Agriculture, Beltsville, Maryland, U.S.A.
}

(Received 18 March 1963)

\begin{abstract}
SUMMARY
The in vitro breakdown of degraded and undegraded varieties of cellulose was examined by using pure strains of bacteria isolated from the rumen of cattle. One strain of Bacteroides succinogenes, two strains of Ruminococcus albus and two strains of Ruminococcus flavefaciens were allowed to ferment ground cellulose powder (prepared from filter paper), cellulose powder (Whatman) and undegraded cotton fibres, the extent of breakdown being followed by loss of weight of the insoluble substrate. All five organisms were highly active on degraded ground cellulose powder and dissolved $72-90 \%$, but only one organism, B. succinogenes strain $\mathrm{s}-85$, was equally effective on cellulose powder (Whatman) or on undegraded cotton fibres. $R$. flavefaciens strain FD-1 was somewhat less potent on the latter substrates, achieving 40 and $60 \%$ dissolution, respectively, of cellulose powder (Whatman) and cotton fibres. $R$. albus strain 7 and $\boldsymbol{R}$. flavefaciens strain c-94 had negligible effects on cotton fibres (10 and $0 \%$ solubilization, respectively). R. albus strain $\mathrm{D}-89$, producing $40 \%$ solubilization of cotton fibres, was intermediate in activity between $R$. albus strain $\boldsymbol{\gamma}$ and $\boldsymbol{R}$. flavefaciens strain FD-1. Cell-free preparations from culture filtrates of $B$. succinogenes strain s-85 gave only $4 \%$ breakdown of ground cellulose powder and up to $9 \%$ breakdown of cellulose powder (Whatman) in 17 days. Cell-free filtrates from the metabolism fluid of $\boldsymbol{R}$. flavefaciens strain FD-1 or from the disintegrated organisms brought about 46 and $36 \%$ solubilization, respectively, of ground cellulose powder, but failed to attack cotton fibres. The results support the view that the capacity of an organism or cell-free enzyme to attack any one particular form of cellulose is no criterion of its ability to attack less degraded or undegraded types of cellulose.
\end{abstract}

\section{INTRODUCTION}

Several attempts have been made to isolate and describe the activity of rumen cellulolytic micro-organisms by using cellulosic substrates previously degraded by chemical or physical treatments and hence rendered more susceptible to biological attack. Thus, acid-treated and ball-milled cotton has been used by Hungate $(1950 a, b)$, a ball-milled filter paper by Bryant \& Burkey (1953 $a$ ) and soluble cellulose derivatives, such as carboxymethylcellulose, by Kitts, Carr \& Underkofler (1954) and Underkofler, Kitts \& Smith (1953). The micro-organisms in question have not, however, been examined on native undegraded cellulosic substrates such as 
cotton fibres, although it is known that this form of cellulose can be readily and completely dissolved in vitro by a mixed population from the rumen of sheep (Halliwell, 1957b, 1961 a). The present work compares the in vitro bacterial solubilization of different forms of cellulose, extending from degraded ball-milled filter paper through cellulose powder (Whatman) to undegraded, purified cotton fibres. The bacteria used were pure strains, isolated from bovine rumen, of Bacteroides succinogenes, Ruminococcus albus and Ruminococcus flavefaciens.

\section{METHODS}

General procedures for the preparation of media, isolation of bacteria and descriptions of strains (Bryant \& Burkey, $1953 a$; Bryant \& Doetsch, 1954; Bryant, Small, Bouma \& Robinson, 1958 a), the nature of the three cellulosic substrates, namely, ground cellulose powder prepared by grinding filter paper (Whatman no. 1) in a ballmill (Bryant \& Burkey, 1953a), cellulose powder (Whatman) and dewaxed Texas cotton fibres (Halliwell, 1957 $a$ ) and the determination of residual cellulose (Halliwell, $1957 a$ ), are described in the references cited. Additional details or modifications are given below.

Bovine bacteria. Bacteroides succinogenes strain s-85, Ruminococcus albus strains 7 and D-89 and Ruminococcus flavefaciens strains C-94 and FD-1 were isolated from bovine rumen and then maintained as stab cultures in agar at -50 to $-70^{\circ}$. Two or three loopfuls of the stock cultures were transferred to tubes containing $5 \mathrm{ml}$. cellulose broth and grown at $37^{\circ}$ for $24-48 \mathrm{hr}$. to provide sufficient actively growing inoculum for up to $200 \mathrm{ml}$. of cellulose broth.

Culture media. Cellulose broth was used to grow the organisms and also as a basal medium to examine the cell-free enzymic breakdown of the different forms of cellulose. Broth $(\mathbf{1 0 0 \mathrm { ml }}$ ) contained: $30 \mathrm{ml}$. whole rumen fluid (prepared by expressing rumen fluid through surgical gauze, allowing to stand overnight at $1^{\circ}$ and separating off the middle phase from the lower sediment and upper floating material); $3.75 \mathrm{ml}$. mineral solution $1\left(0.6 \%, \mathrm{w} / \mathrm{v}, \mathrm{K}_{2} \mathrm{HPO}_{4}\right) ; 3.75 \mathrm{ml}$. mineral solution 2 $\left(\mathrm{w} / \mathrm{v}: 0 \cdot 6 \%, \mathrm{KH}_{2} \mathrm{PO}_{4} ; 1 \cdot 2,\left(\mathrm{NH}_{4}\right)_{2} \mathrm{SO}_{4} ; 1 \cdot 2, \mathrm{NaCl} ; 0 \cdot 25, \mathrm{MgSO}_{4} .7 \mathrm{H}_{2} \mathrm{O} ; 0 \cdot 12, \mathrm{CaCl}_{2}\right)$; $0 \cdot 1 \mathrm{ml} .0 \cdot 1 \%$, w/v, resazurin solution; $5 \mathrm{ml} .8 \%, \mathrm{w} / \mathrm{v}, \mathrm{Na}_{2} \mathrm{CO}_{3} ; 2 \mathrm{ml} .2 .5 \%, \mathrm{w} / \mathrm{v}$, cysteine hydrochloride; water to $100 \mathrm{ml}$. The broth was equilibrated with, and maintained under, $\mathrm{O}_{2}$-free $\mathrm{CO}_{2}$. Ground cellulose powder, cellulose powder (Whatman) or dewaxed Texas cotton fibres were incorporated in the medium at a final concentration of about $\mathbf{0} \cdot \mathbf{2} \%, \mathrm{w} / \mathrm{v}$.

Cellulolysis or solubilization of cellulose. In the standard cellulase assay for whole bacteria, the strains were inoculated under $\mathrm{CO}_{2}$ into test tubes $(16 \times 150 \mathrm{~mm}$.) of cellulose broth ( $10 \mathrm{ml}$.) and incubated anaerobically at $37^{\circ}$. In the standard cellulase assay for cell-free preparations an aqueous suspension of cellulose was added to different amounts of culture filtrate as indicated in the text; the assays were made at $37^{\circ}$ under sterile and anaerobic conditions in presence of $\mathrm{CO}_{2}$ and with additional cysteine at the concentration found in the culture medium. Reagents and tubes were sterilized by autoclaving at $120^{\circ}$ and enzyme solutions by filtration.

Solubilization of cellulose was followed by gravimetric estimation of residual cellulose by using sintered-glass filter crucibles, porosity $\mathbf{M}$, medium grade (nominal maximum pore size 10-15 $\mu$ ) for cellulose powders, or porosity $\mathrm{C}$, coarse grade $(40-60 \mu)$ for cotton fibres. With the pure cultures used here the washing procedure 
with $\mathrm{HCl}, \mathrm{NH}_{4} \mathrm{OH}$, Teepol and ethanol (Halliwell, 1957 a), for the removal of contaminating non-cellulosic material from mixed rumen bacterial fermentations, was not required. Residual cellulose was washed copiously with distilled water, dried overnight and weighed: the 'enzyme blank' (bacteria incubated in cellulose-free media) gave negligible values after washing and filtration.

Cell-free enzyme preparations. Large-scale cultures with about $400 \mathrm{ml}$. cellulose broth containing $\mathbf{0 . 2} \%$ ground cellulose powder, were inoculated from actively growing cultures of Bacteroides succinogenes strain s-85 or Ruminococcus flavefaciens strain FD-1, grown for the preceding $24-48 \mathrm{hr}$. in an identical medium. At suitable intervals the large-scale cultures were agitated temporarily with a magnetic stirrer to provide homogeneous suspensions for sampling. The cultures were regassed with $\mathrm{CO}_{2}$ during and after sampling. After the desired stage of fermentation had been reached the cultures were centrifuged at $27000 \mathrm{~g}$ for $20 \mathrm{~min}$. at $3^{\circ}$ (Servall Machine, Model RC2, Rotor SS-34, Ivan Sorvall, Inc., Norwalk, Conn., U.S.A.) and the cellfree supernatant phase removed and maintained under $\mathrm{CO}_{2}$ for assay. In some experiments the precipitated bacteria were also disintegrated in a Mini-Mill (Gifford-Wood Co., Hudson, New York) under $\mathrm{CO}_{2}$ and cooled in ice. Extensive breakage of organisms required 30-50 min. treatment in the Mill, and was judged by safranin stained smears.

Alkali solubility of cellulosic substrates. Dewaxed Texas cotton fibres, cellulose powder (Whatman), and a hydrocellulose (prepared by soaking absorbent cotton wool in $11 \mathrm{~N}-\mathrm{HCl}$; Halliwell, $1957 a$ ), were air-dried materials. Ground cellulose powder and ground hydrocellulose, which were prepared in the usual manner in a ball mill (Bryant \& Burkey, 1953a; Hungate, 1950a), were stored and used in aqueous suspension. The hydrocellulose and its ground counterpart had been used as cellulosic substrates in earlier work with rumen micro-organisms, but in the present work they were used only for comparative purposes in the alkaline solubility estimations.

About $50 \mathrm{mg}$. of each form of cellulose in water was mixed in a test tube with an equal volume $(6 \mathrm{ml}$.) of $2 \mathrm{~N}-\mathrm{NaOH}$, the suspension heated in a boiling water bath for $15 \mathrm{~min}$. under a glass pear-bulb, cooled for $5 \mathrm{~min}$. and transferred quantitatively to a sintered glass crucible (porosity $M$ ) by washing with $20 \mathrm{ml}$. $\mathrm{N}-\mathrm{NaOH}$. The cellulose was sucked almost dry, washed with $40 \mathrm{ml}$. $\mathrm{N}-\mathrm{NaOH}$, again sucked almost dry, and washed with water, $0 \cdot 1 \mathrm{~N}-\mathrm{H}_{2} \mathrm{SO}_{4}$ and water until neutral. The crucible + cellulose were dried overnight at $105^{\circ}$ and weighed.

\section{RESULTS}

\section{Bacterial solubilization of ground cellulose powder, cellulose powder and dewaxed cotton fibres}

Bacteroides succinogenes strain s-85, Ruminococcus albus strains 7 and D-89, $\boldsymbol{R}$. flavefaciens strains C-94 and FD-1 were grown in cellulose broth containing about $\mathbf{0} \cdot \mathbf{2} \%$ ground cellulose powder (Whatman) or dewaxed cotton fibres. It is evident from Table 1 that the five organisms attacked ground cellulose powder and, with the exception of $\boldsymbol{B}$. succinogenes strain s-85, attacked this powder, a degraded substrate, more effectively than they did fibres. Only $B$. succinogenes strain $\mathrm{s}-85, R$. flavefaciens strain FD-1 and possibly $R$. albus strain D-89 gave significant breakdown of undegraded cellulose as found in cotton fibres. 
In an attempt to promote more rapid and extensive attack on cotton fibres we re-examined some of the organisms recorded in Table 1 after incorporating cellobiose at $0.02 \%$ final concentration in the medium. The results (Table 2 ) confirmed

Table 1. Solubilization of ground cellulose powder and dewaxed cotton fibres by rumen bacteria

Conditions: standard cellulase assay (see Methods). Initial weight of ground cellulose powder was $23 \mathrm{mg}$. (average) and of cotton fibres $20 \mathrm{mg}$. Period of incubation for ground cellulose powder was 5 days and for cotton fibres 7 days.

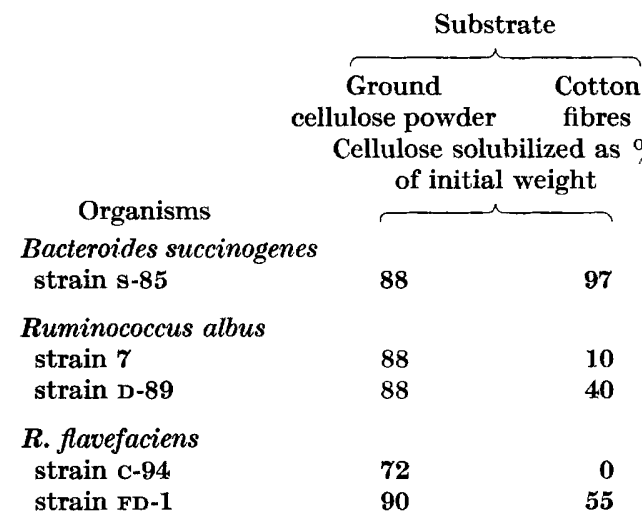

Table 2. Solubilization of derwaxed cotton fibres in presence of cellobiose

Conditions: as in Table 1 but with cellobiose in the medium at $0.02 \%$ final concentration. Initial weight of cotton fibres was $21 \mathrm{mg}$. (average).

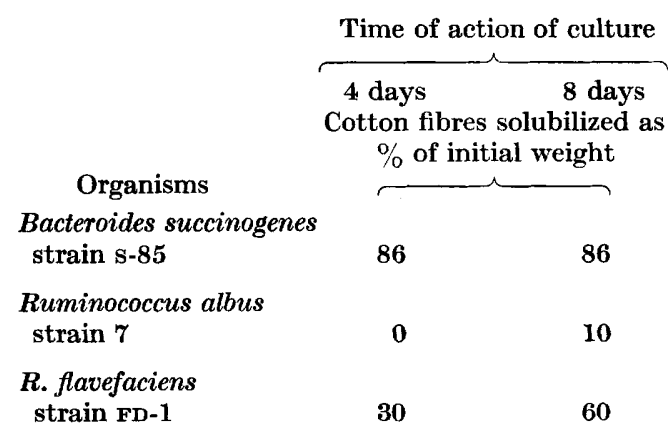

the cellulolytic nature of $\boldsymbol{B}$. succinogenes strain s-85 and of $\boldsymbol{R}$. flavefaciens strain FD-1, whereas $R$. albus strain 7 once again showed little inclination to solubilize undegraded cellulose of cotton fibres. This suggests that the cellulolytic activity of $\boldsymbol{R}$. albus strain 7 is restricted to simpler forms of cellulose (Table 1 ).

Cellulose powder (Whatman) appears to retain some of the properties of native cellulose more than do certain other powdery forms of cellulose; it is more soluble in $\mathrm{N}$-alkali than cotton fibres (see Discussion) but resists solubilization by cell-free cellulolytic filtrates from fungi although not to the same degree as do cotton fibres (Halliwell, 1961b). If particle size were the only obstacle to microbial breakdown of fibrous cellulose we should expect the powdery nature of cellulose powder 
(Whatman) to encourage attack by those organisms which find difficulty in metabolizing fibres. Three amounts of cellulose powder (Whatman), about 10, 20 and $50 \mathrm{mg}$., were supplied to Bacteroides succinogenes strain s-85, Ruminococcus flavefaciens strain FD-1 and $R$. albus strain 7 . At all substrate concentrations the first two strains showed rapid breakdown of cellulose up to the fourth day of fermentation, whilst $R$. albus displayed only feeble activity extending to the second day (Figs. 1,2).

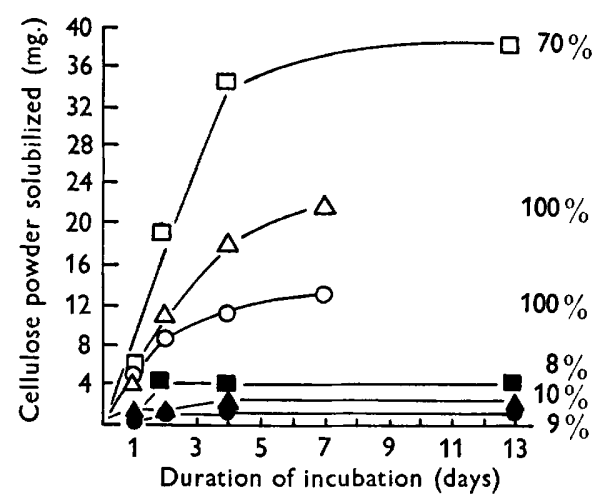

Fig. 1

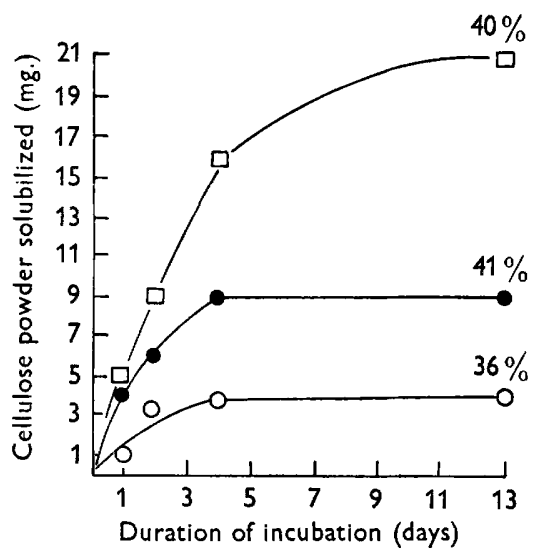

Fig. 2

Fig. 1. The effect of time of incubation on bacterial cellulolysis of cellulose powder (Whatman). Conditions: standard cellulase assay wich Bacteroides succinogenes strain s-85; initial weight of cellulose $13 \mathrm{mg} ., \bigcirc ; 22 \mathrm{mg} ., \triangle$; $54 \mathrm{mg} ., \square$. Ruminococcus albus strain 7 ; initial cellulose $11 \mathrm{mg}$., $\odot ; 20 \mathrm{mg}$., $\Delta ; 51 \mathrm{mg}$, $\square$. Cellulose incubated in absence of bacteria for 13 days lost no weight. Percentages near curves indicate the final extent of solubilization of the initial cellulose.

Fig. 2. The effect of time of incubation on bacterial cellulolysis of different amounts of cellulose powder (Whatman). Conditions : standard cellulase assay with Ruminococcus flavefaciens strain FD-1; initial weight of cellulose $11 \mathrm{mg}$., $O$; $22 \mathrm{mg}$., $\bullet$; $53 \mathrm{mg}$., $\square$. Other details as in Fig. 1.

After the fourth day the rate of solubilization of cellulose decreased with B. succinogenes strain $\mathbf{s - 8 5}$ and $\boldsymbol{R}$. flavefaciens strain FD-1 and complete hydrolysis was achieved only by the former organism in 7 days. With $\boldsymbol{R}$. flavefaciens strain FD-1, increasing the fermentation period by 9 days produced little change in the figure of about $40 \%$ breakdown attained after the first 4 days at the lower cellulose concentrations. At all three cellulose concentrations $R$. albus strain 7 dissolved no more than $10 \%$ of the substrate in 2 or 13 days fermentation.

\section{Cellulolytic enzymes from Bacteroides succinogenes strain $s-85$ and from Ruminococcus flavefaciens strain $F D-1$}

The action of cell-free enzyme preparations from Bacteroides succinogenes strain $s-85$ on ground cellulose powder and on cellulose powder (Whatman). Strain s-85 was grown in $400 \mathrm{ml}$. broth containing $\mathbf{0 \cdot 2 2} \%$ ground cellulose powder, as described in Methods. After $29 \mathrm{hr}$. the organisms had decreased the amount of cellulose to $37 \%$ of its initial value and to $21 \%$ in a further $12 \mathrm{hr}$. The culture was allowed a further $23 \mathrm{hr}$. (total $64 \mathrm{hr}$.) to attack most of the remaining cellulose and thus to encourage release of any adsorbed enzyme from its cellulosic substrate (see Halliwell, 1961 b). The 
culture was centrifuged to obtain the aqueous phase which was sterilized by filtration; $10 \mathrm{ml}$. of this cell-free enzyme solution were incubated with $\mathbf{2 0} \mathrm{mg}$. ground cellulose powder + cysteine at $37^{\circ}$ for 22 days. This produced only a $4 \%$ loss of weight of cellulose. Other cultures of $B$. succinogenes strain s-85, grown under identical conditions to those described, metabolized $86 \%$ of ground cellulose powder in $44 \mathrm{hr}$. and $88 \%$ in $72 \mathrm{hr}$. Cell-free culture filtrates were obtained at both stages of attack by the standard procedures and their activities measured by using $20 \mathrm{mg}$. cellulose powder (Whatman) and $20 \mathrm{ml}$. of each of the enzymic filtrates. These dissolved only 9 and $3 \%$, respectively, of the available cellulose powder (Whatman) in 17 days at $37^{\circ}$. The small extent of breakdown of ground cellulose powder and cellulose powder (Whatman) is not considered significant in view of the nature of these substrates (see Discussion).

The action of cell-free enzyme preparations from Ruminococcus flavefaciens strain FD-1 on ground cellulose powder and on dewaxed cotton fibres. Tables 1 and 2 and Figs. 1 and 2 indicate that $R$. flavefaciens strain FD-1 was as active as Bacteroides succinogenes strain s-85 on ground cellulose powder, but was not as effective in solubilizing less-degraded substrates such as cellulose powder (Whatman) and cotton fibres. Thus $\boldsymbol{R}$. flavefaciens strain FD-1, like $B$. succinogenes strain s-85, dissolved ground cellulose powder to within $90 \%$ of completion, but gave only $40-60 \%$ loss of weight of cellulose powder (Whatman) and cotton fibres, as compared with the $100 \%$ loss effected by $B$. succinogenes strain s-85. The latter organism did not provide a cell-free cellulase preparation producing marked breakdown of either of the substrates tested and the results indicate that $R$. flavefaciens strain FD-1 was the only remaining bacteria likely to possess this enzyme system.

Ruminococcus flavefaciens strain FD-1 was grown by the standard procedure in $400 \mathrm{ml}$. broth $+0 \cdot 2 \%$ ground cellulose. Of the cellulose 36 and $80 \%$ was catabolized after 18 and $40 \mathrm{hr}$., respectively. The older culture supplied two enzyme preparations: the first was the supernatant phase obtained by centrifuging the culture medium; the second was prepared by resuspending the sediment in the minimum necessary volume of some of the above supernatant phase followed by treatment in the Mini-mill disintegrator whereby the enzyme was released into the aqueous phase. This was collected by centrifugation as described earlier. The two enzyme preparations, sterilized by filtration, were incubated in 15 and $5 \mathrm{ml}$. samples each with $20 \mathrm{mg}$. ground cellulose powder for 20 days during which period they solubilized 46 and $36 \%$, respectively, of the substrate. Samples $(20 \mathrm{ml}$.) of the first enzyme preparation were also incubated for 20 days with $10 \mathrm{mg}$. dewaxed cotton fibres; no loss of weight of cellulose was observed.

\section{DISCUSSION}

In the field of cellulose metabolism by micro-organisms or cell-free enzyme preparations, difficulties of definition are more important than real experimental discrepancies. There is much to be said for adhering only to the terms $\beta$-polyglucosidase or 1,4- $\beta$-glucanase for the enzymes which attack polymers of the cellulose type, and for reserving the term cellulase until such time as the mechanism that accomplishes the initial degradation or sensitization of undegraded cellulose or native cotton fibres has been elucidated. The same difficulties of interpretation arise with the term 'cellulolytic organism' because not all organisms thus styled can 
attack cotton fibres. Whilst one is entitled to use the term cellulolytic for an organism that attacks any 1,4- $\beta$-glucan, such organisms are undoubtedly divided into two groups in accordance with their ability or inability to act on cotton fibres.

Soluble cellulose derivatives or similar biologically susceptible forms of insoluble but degraded cellulose are often used as substrates for enzymes in whole organisms or in the cell-free state. The results obtained, however, are difficult to assess in absence of simultaneous studies with an undegraded substrate such as cotton fibre. Whilst all forms of cellulose are believed to be chemically identical in consisting solely of 1,4- $\beta$-linked anhydroglucose units, there are marked differences between them in physical properties such as chain length and the presence of crystalline and amorphous regions. A distinction between various types of cellulose is shown by their relative susceptibilities to alkali. Five cellulosic substrates (dewaxed cotton fibres, cellulose powder (Whatman), a hydrocellulose powder prepared from absorbent cotton wool by soaking in concentrated $\mathrm{HCl}$, the same hydrocellulose after grinding in a ball-mill, ground cellulose powder prepared from filter-paper) were digested with $\mathrm{N}-\mathrm{NaOH}$ for 15 min. as described in Methods, and lost $0,17,16$, 17 and $21 \%$ of their weight, respectively (corrected for moisture content). A more comprehensive estimate of the smaller molecular chains of cellulose is given by the $\beta$ - and $\gamma$-cellulose contents. These two fractions, arbitrarily defined as the material soluble in $17.5 \%(\mathrm{w} / \mathrm{w}) \mathrm{NaOH}$ at $20^{\circ}$, contain molecules with a degree of polymerization from about 10 to 200. $\alpha$-Cellulose is the fraction insoluble in the same concentration of alkali and has chains with a degree of polymerization greater than 200 . The $\beta-+\gamma$-cellulose contents of dewaxed Texas cotton fibres and of cellulose powder (Whatman) were 2 and $30 \%$, respectively, as determined by loss of weight on $50 \mathrm{mg}$. of each substrate and corrected for moisture contents. This difference in physical properties between celluloses is reflected in the relative activities of the rumen bacteria examined in this report. Five organisms, Bacteroides succinogenes strain s-85, both strains of Ruminococcus albus and both strains of $\boldsymbol{R}$. flavefaciens, were most effective in solubilizing a large proportion (72-90\%) of a degraded ground cellulose powder (Table 1 ); but only $B$. succinogenes strain s-85 produced a comparable degree of cellulolysis of undegraded cotton fibres and of cellulose powder (Whatman). In this respect it is similar to mixed rumen micro-organisms (Halliwell, $1957 b, 1961 a$ ). $R$. flavefaciens strain FD-1 and $R$. albus strain D-89 were less effective in rate and extent of cellulolysis and were the only other strains to achieve marked breakdown of cotton fibres, 55 and $40 \%$, respectively (Tables 1,2 ). On cellulose powder (Whatman) the action of $\boldsymbol{R}$. flavefaciens strain FD-1, the most effective of the ruminococci in Table 1 , was similarly restricted to $40 \%$ solubilization of the substrate, even with prolonged incubation (Fig. 2). R. albus strain 7 and R. flavefaciens strain C-94 produced extensive solubilization (88 and $72 \%$ ) of ground cellulose powder but only 10 and $0 \%$ breakdown of cotton fibres (Table 1). Other strains of $R$. albus which did not attack even the ground cellulose powder have been described (Bryant et al. 1958b). As only one strain of $B$. succinogenes was available for the present study, it is not known whether this species would, in general, more extensively solubilize fibrous forms of cellulose as compared to ruminococci. It is of interest in this respect that B. succinogenes was found in much greater numbers than ruminococci in the rumen of a cow fed wheat-straw, but ruminococci were more numerous when good quality alfalfa hay was fed (Bryant \& Burkey, 1953 b). 
It has frequently been suggested that fibrous forms of cellulose are unsuitable substrates for rumen micro-organisms because of the relatively small surface area exposed to attack, and recourse has been made to finely ground varieties of cellulose. An increased susceptibility to biological attack that accompanies the transition from fibrous to powdery cellulose is liable to be associated not only with increased surface area, but also with degradative changes in the cellulose molecules. If the surface area of the cellulose were of paramount importance in favouring bacterial attack then cellulose powder (Whatman) should be broken down to a greater extent than cotton fibres. The results shown in Figs. 1 and 2 do not support this view. R. albus strain 7 and $\boldsymbol{R}$. flavefaciens strain FD-1 found cellulose powder (Whatman) just as difficult to solubilize as cotton fibres, suggesting that this powdered cellulose retained some of the characteristics of the fibrous material.

The small degree of cellulolysis of ground cellulose powder $(4 \%)$ and cellulose powder (Whatman) (3-9\%) shown by cell-free enzyme preparations from Bacteroides succinogenes strain $\mathrm{s}-85$ is probably insignificant as far as undegraded cellulose is concerned, since the effect might be confined to the smaller cellulosic molecules produced in the manufacture. This lack of cellulolytic activity shown by cell-free systems from $B$. succinogenes strain $\mathbf{s - 8 5}$ is in marked contrast to the pronounced activity of the intact organism on all three forms of cellulose (Tables 1, 2; Figs. 1, 2). $\boldsymbol{R}$. flavefaciens strain FD-1, although as active on ground cellulose powder as $B$. succinogenes strain $\mathrm{s}-85$, was only about half as effective as $B$. succinogenes strain $\mathbf{s - 8 5}$ on cellulose powder (Whatman) and on cotton fibres, but yielded cellfree enzyme preparations which solubilized up to $46 \%$ of ground cellulose powder. The same preparations did not attack cotton fibres, suggesting that different mechanisms are responsible for the breakdown of degraded and undegraded cellulose.

\section{REFERENCES}

Bryant, M. P. \& Burkey, L. A. (1953a). Cultural methods and some characteristics of some of the more numerous groups of bacteria in the bovine rumen. J. Dairy Sci. 36, 205.

Bryant, M. P. \& Burkey, L. A. $(1953 b)$. Numbers and some predominant groups of bacteria in the rumen of cows fed different rations. J. Dairy Sci. 36, 218.

Bryant, M. P. \& Doetsch, R. N. (1954). A study of actively cellulolytic rod shaped bacteria of the bovine rumen. J. Dairy Sci. 37, 1176.

Bryant, M. P., Small, N., Bouma, C. \& Robinson, I. M. (1958a). The characteristics of ruminal anaerobic cellulolytic cocci and Cillobacterium cellulosolvens N.Sp. J. Bact. 76, 529.

Bryant, M. P., Small, N., Bouma, C. \& Robinson, I. M. (1958b). Studies on the composition of the ruminal flora and fauna of young calves. J. Dairy Sci. 41, 1747.

Halliwell, G. (1957 a). Cellulolysis by rumen micro-organisms. J. gen. Microbiol. 17, 153.

Halliwell, G. (1957b). Cellulolytic preparations from micro-organisms of the rumen and from Myrothecium verrucaria. J. gen. Microbiol. 17, 166.

Halliweld, G. $(\mathbf{1 9 6 1}$ a). In Digestive Physiology and Nutrition of the Ruminant. Ed. by D. Lewis. London: Butterworths.

HALliwell, G. (1961 b). The action of cellulolytic enzymes from Myrothecium verrucaria. Biochem. J. 79, 185.

Hungate, R. E. (1950a). The anaerobic mesophilic cellulolytic bacteria. Bact. Rev. 14, 1.

Hungate, R. E. (1950b). Mutualisms in protozoa. Annu. Rev. Microbiol. 4, 53.

KitTs, W. D., CARR, P. H. \& Underkofler, L. A. (1954). Isolation of cellulose-digesting microorganisms of the rumen. Iowa St. Coll. J. Sci. 29, 129.

Underkofler, L. A., Kitts, W. D. \& Smith, R. L. (1953). Soluble cellulose derivatives as substrate for ruminal microorganisms. Arch. Biochem. Biophys. 44, 492. 